\title{
PROCESSING AND PROPERTIES OF MICROCRYSTALLINE, SUBMICROCRYSTALLINE, AND NANOCRYSTALLINE ALLOY 718
}

\author{
V.A. Valitov, O.A. Kaibyshev, Sh. Kh. Mukhtarov \\ B.P. Bewlay*, M.F.X. Gigliotti* \\ Institute for Metals Superplasticity Problems, 39 Khalturina Street, Ufa 450001, Russia. \\ *General Electric Corporate Research and Development, P.O. Box 8, \\ Schenectady, NY 12301, USA
}

\begin{abstract}
This paper will describe the refinement of a coarse-grained alloy 718 microstructure to microcrystalline (MC), submicrocrystalline (SMC), and nanocrystalline (NC) structures by high-strain plastic deformation. Dynamic recrystallization occurs during high-strain hot plastic deformation leading to the formation of an MC structure with a grain size of $1-4 \mu \mathrm{m}$. The $\delta$ phase precipitated as plates, and during deformation, these plates were broken up into smaller particles. These particles take the form of ellipsoids located mainly at the triple junctions of the recrystallized grains. A SMC structure was formed in alloy 718 during severe plastic deformation in the temperature range $0.67-0.60 \mathrm{~T}_{\mathrm{m}}$. During dynamic and static recrystallization, the MC structure transformed to the SMC structure, and $\delta$-phase plates precipitated uniformly throughout the matrix. The size of these precipitates was similar to the matrix grain size (0.2-0.5 $\mu \mathrm{m})$. Further reduction in the processing temperature to $0.5 \mathrm{~T} \mathrm{~m}$ provided additional refinement of the microstructure to a grain size of less than $0.1 \mu \mathrm{m}$.

The formation of NC structures in alloy 718 by cold severe plastic deformation $\left(0.18 \mathrm{~T}_{\mathrm{m}}\right)$ was also studied. The microstructure evolution during combined torsion and compression was examined. With increasing strain, a cellular structure was formed, which was then refined to a granular structure with a grain size of $30-40 \mathrm{~nm}$, with high angle grain boundaries and a high level of residual stress within the grains. The influence of the initial grain size on deformation mechanisms during superplastic deformation of alloy 718 was also studied. For grain sizes of $0.1-0.08 \mu \mathrm{m}$, superplasticity $(\delta=350 \%, \mathrm{~m}=0.37)$ was observed at a temperature of $600^{\circ} \mathrm{C}$ and a strain rate of $1.5 \times 10^{-4} \mathrm{~s}^{-1}$.
\end{abstract}

\section{Introduction}

Application of superplastic (SP) forming of nickel base alloys with MC structures is limited by the fact that superplasticity only occurs at high homologous temperatures $\left(0.8-0.85 \mathrm{~T}_{\mathrm{m}}\right)$ and low strain rates $\left(10^{-3}-10^{-4} \mathrm{~s}^{-1}\right)[1-3]$. SMC and NC materials $[4,5]$ display unique physical and mechanical properties $[6,7]$. There is presently substantial interest in structure-property relationships in materials with SMC and NC structures [6-8], but there is relatively little previous work on the mechanical behavior of nickel base alloys with SMC structures. There have been few previous studies of the formation of SMC and NC structures in complex nickel base alloys, and the effect of these structures on properties. The goal of the present paper is to describe the processing regimes for generating $\mathrm{MC}, \mathrm{SMC}$ and $\mathrm{NC}$ structures in alloy 718 , and to evaluate the effect of these microstructures on SP properties.

\footnotetext{
Superalloys 718, 625, 706 and Various Derivatives

Edited by E.A. Loria

TMS (The Minerals, Metals \& Materials Society). 2001
} 


\section{Materials and Experimental Procedure}

The chemical composition of the Alloy 718 that was studied is shown in Table 1. Samples of Alloy 718 were machined from $200 \mathrm{~mm}$ diameter billets. Compression and tension tests were conducted over a wide range of temperatures $\left(500-1100^{\circ} \mathrm{C}\right)$ and strain rates $\left(1.5 \times 10^{-4}-1.3 \times 10^{-2} \mathrm{~s}^{-1}\right)$. Cylindrical samples, $10 \mathrm{~mm}$ in diameter and $15 \mathrm{~mm}$ in height, were deformed in compression using a SCHENK-PSA testing machine. Larger samples (40-80 mm in diameter and 10-12 mm long), were generated with SMC structures on 100 and 630 tonne-force presses using processing conditions derived from the results of the smaller samples. Tensile SP characteristics were measured using sheet samples, with gauge dimensions of $10 \times 5 \times 2 \mathrm{~mm}$. Transmission electron microscope (TEM) investigations of deformed samples were performed using a JEM-2000EX.

Table 1. Composition of the alloy 718 that was studied.

\begin{tabular}{|c|c|c|c|c|c|c|c|}
\hline \multicolumn{7}{|c|}{ Concentrations (wt. \%) } \\
\hline $\mathrm{C}$ & $\mathrm{Cr}$ & $\mathrm{Mo}$ & $\mathrm{Fe}$ & $\mathrm{Al}$ & $\mathrm{Ti}$ & $\mathrm{Nb}$ & $\mathrm{Ni}$ \\
\hline 0.05 & 19 & 3.1 & 18 & 0.5 & 1.0 & 5.1 & balance \\
\hline
\end{tabular}

In order to obtain the high strains required for generating NC structures, high pressure deformation was generated using a Bridgman anvil. The dimensions of the initial samples were $4 \mathrm{~mm}$ in diameter and 0.7 $\mathrm{mm}$ thick. In this case the true strain, $\varepsilon$, at a point located at a radius, $r$, is determined as a shear strain:

$$
\varepsilon=2 \pi \mathrm{rN} / \sqrt{ } 3 \mathrm{~L}
$$

where $\mathrm{N}$ is the number of anvil rotations, and $\mathrm{L}$ is the sample thickness ( $\mathrm{mm}$ ).

\section{Experimental Results}

\section{$\underline{3.1 \text { Initial Alloy } 718 \text { Microstructure }}$}

In the initial condition, the alloy 718 had a completely recrystallized structure with a grain size of $\sim 40 \mu \mathrm{m}$, as shown in Figure 1(a). TEM studies showed that within the $\gamma$ phase grains there were disk-like $\gamma^{\prime \prime}$ phase precipitates which were uniformly distributed. The diameter of $\gamma^{\prime \prime}$-phase disks was about $60 \mathrm{~nm}$,

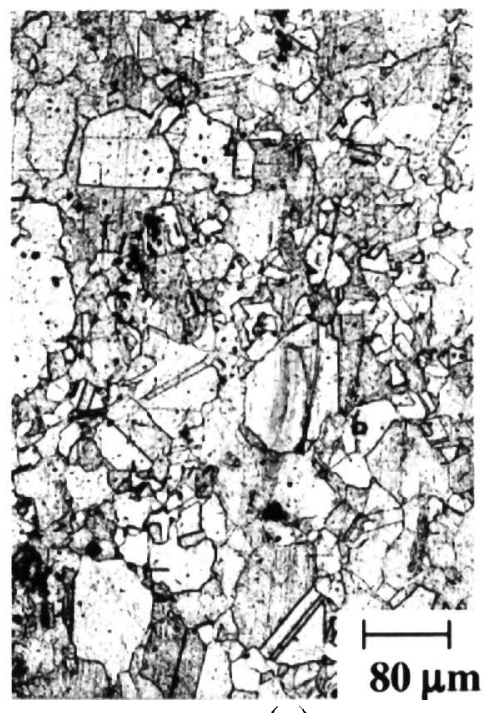

(a)

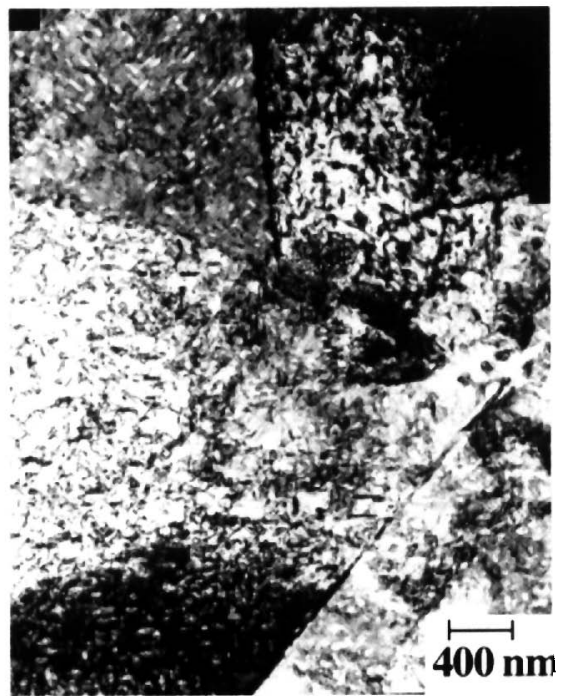

(b)

Figure 1. Microstructure of the alloy 718 in the initial condition. 
and their thickness was $\sim 20 \mathrm{~nm}$. The $\gamma^{\prime \prime}$-phase precipitates were also observed on grain boundaries, as shown in Figure 1(b).

\section{$\underline{3.2 \text { Formation of Microcrystalline Structures }}$}

Microstructure evolution The following microstructural changes were observed after examination of the deformed samples. After deformation of the alloy with the strain rate $5.5 \times 10^{-4} \mathrm{~s}^{-1}$ at $800^{\circ} \mathrm{C}$, metallographic texture was observed in the central zone of the deformed samples. Near the end face (zone of lower deformation), grains with twisting boundaries were observed. Deformation at $850^{\circ} \mathrm{C}$ led to the formation of fine recrystallized grains $(1-2 \mu \mathrm{m})$ in the deformed grains. On increasing the deformation temperature from 900 to $950^{\circ} \mathrm{C}$, the size of recrystallized grains grew insignificantly and were in the range of 3 to $4 \mu \mathrm{m}$; the volume fraction of recrystallized grains increased from 19.6 to $32.8 \%$. Deformation at temperatures $1050^{\circ} \mathrm{C}$ and 1100 ${ }^{\circ} \mathrm{C}$ led to dynamic recrystallization and structures with a grain sizes of 24 and $41 \mu \mathrm{m}$, respectively.

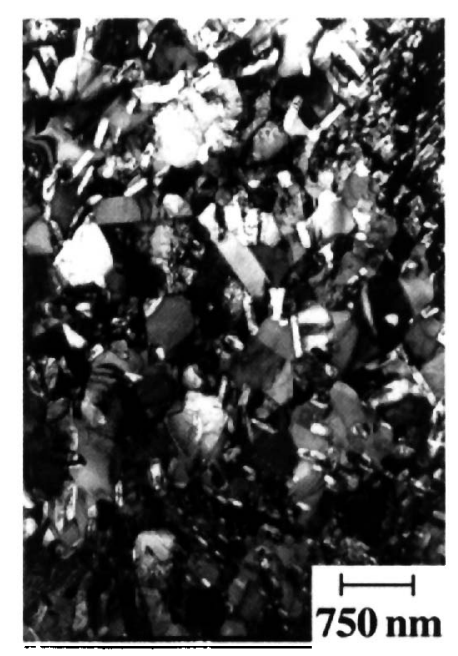

Figure 2. Microstructure of the alloy 718 after forging at a strain rate of $5.5 \times$ $10^{-3} \mathrm{~s}^{-1}$ and $850^{\circ} \mathrm{C}$ to generate an $\mathrm{MC}$ structure.

After deformation at a strain rate of $5.5 \times 10^{-3} \mathrm{~s}^{-1}$ and $950^{\circ} \mathrm{C}$, the recrystallized grain size was $4 \mu \mathrm{m}$. As the deformation temperature increased, the volume and size of recrystallized grains increased. At $1050^{\circ} \mathrm{C}$ recrystallized grains $(\sim 10 \mu \mathrm{m}$ in size $)$ were observed throughout the sample. After deformation at $1100^{\circ} \mathrm{C}$ the size of recrystallized grains increased to $32 \mu \mathrm{m}$. Reduction of the deformation temperature to $850^{\circ} \mathrm{C}$, at the same strain rate of $5.5 \cdot 10^{-3} \mathrm{~s}^{-1}$, generated an $\mathrm{MC}$ structure with a grain size of $\sim 1 \mu \mathrm{m}$, as shown in Figure 2 .

\section{Evolution of coarse grain structures during hot deformation}

In order to investigate the formation of MC structures in alloy 718 , the microstructures of samples that were subjected to strains of $5-75 \%$ in the two-phase $(\gamma+\delta)$ region at $925{ }^{\circ} \mathrm{C}$ and a strain rate of $5 \cdot 10^{-4} \mathrm{~s}^{-1}$ were examined. In addition to the deformation processes, precipitation of lamellar $\delta$-phase occurs, and these precipitates affect the grain structure. At the initial stage of deformation, $\delta$-phase plates near the boundaries grow into the grains, as shown in Figure 3(a). The interaction of lattice dislocations with $\delta$-phase precipitates generates dislocation walls even at small strains. Increasing the strain to $25 \%$ leads to a significant increase in the volume fraction of $\delta$-phase plates that were precipitated in almost all grains in one or two directions, as shown in Figure 3(b). Analysis of the morphology of $\delta$-phase precipitates indicates that the precipitates break up during deformation. Metallographic texture was also observed. Coarse grains were elongated in the tensile direction, and the $\delta$-phase plates were similarly aligned. Sub-grains were formed and they gradually transformed into recrystallized grains with high-angle grain boundaries.

Increasing the strain to $50 \%$ results in the further break-up and bending of $\delta$-phase plates, as shown in Figure 3(c). Bending of plates was accompanied by the formation of transverse boundaries. On the boundary surface of $\delta$-phase particles near the boundary, banded contrast was observed. This was probably indicative of the high-angle misorientation of interfaces of these particles with the matrix. Growth of intragranular particles of $\delta$-phase was also observed. These particles provide the nucleation of the sub-grains that developed a size that was comparable with the distance between particles $(0.3-0.8 \mu \mathrm{m})$. The size of recrystallized grains was $2-4 \mu \mathrm{m}$. At strains of $75 \%$, recrystallized grains were observed 


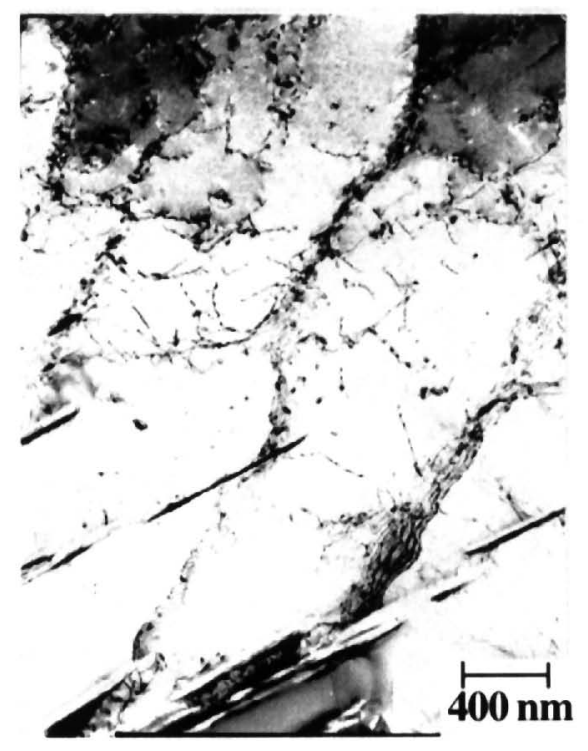

(a)

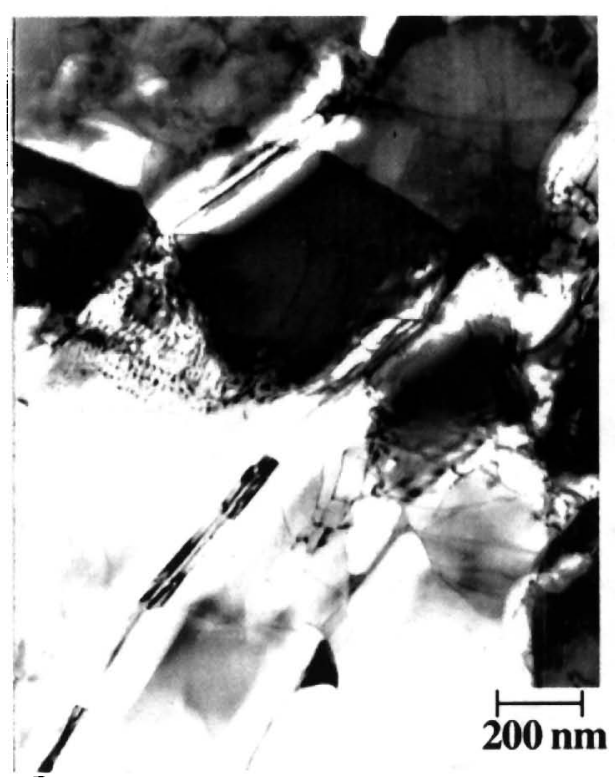

(c)

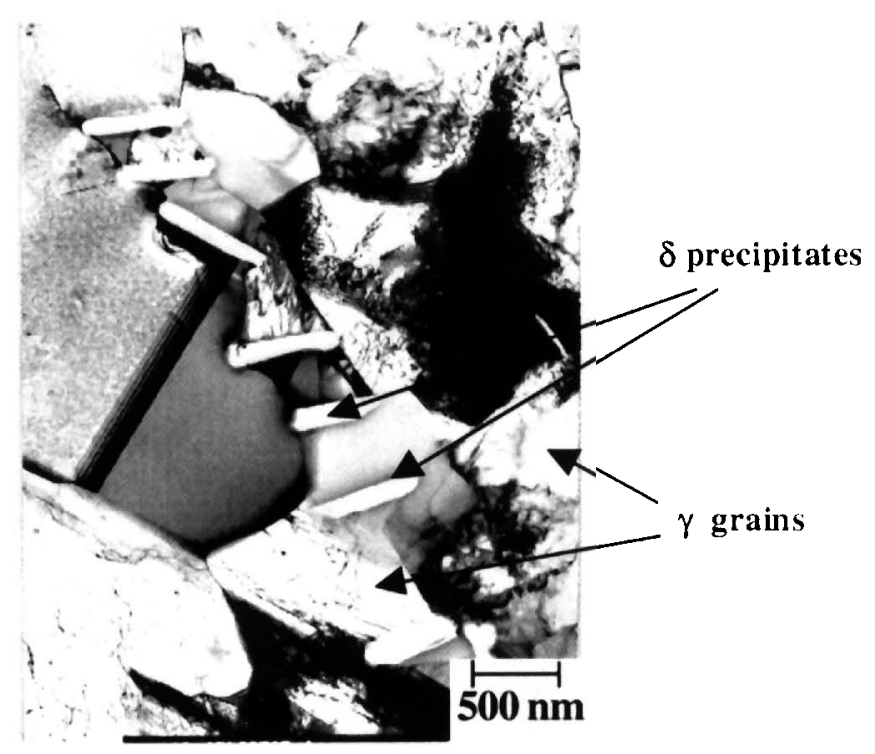

(b)

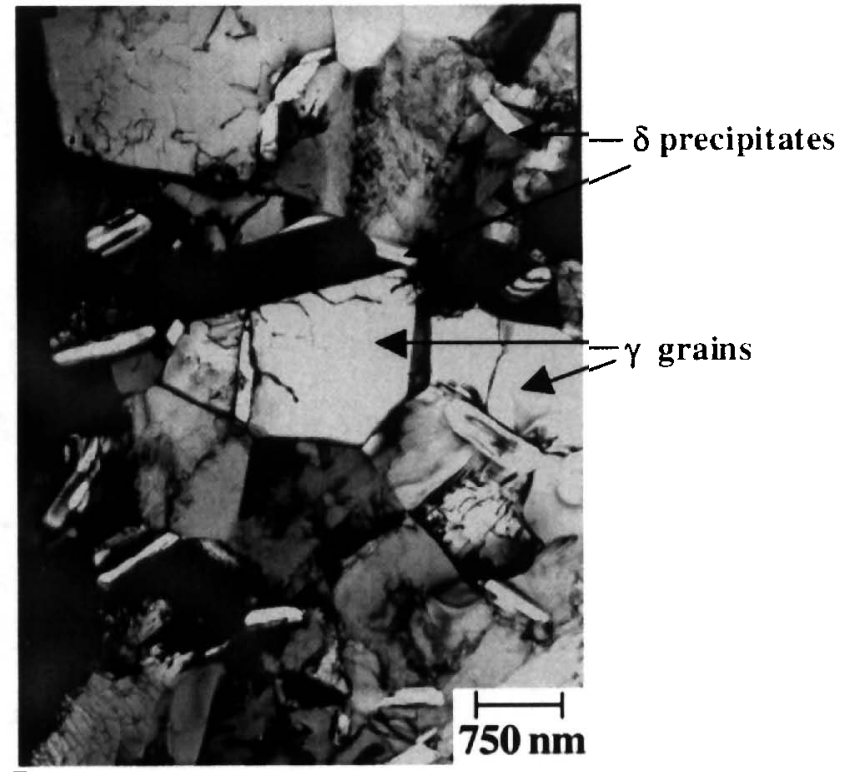

(d)

Figure 3. Microstructure of alloy 718 after compression testing at a strain rate of $5.5 \times 10^{-4} \mathrm{~s}^{-1}$ and $925{ }^{\circ} \mathrm{C}$ to strains of: (a) $5 \%$, (b) $25 \%$, (c) $50 \%$, and (d) $75 \%$.

throughout the material, as shown in Figure 3(d).

\section{$\underline{\text { 3.3 Formation of Submicroctystalline Structures }}$}

High strain thermomechanical processing (TMP) was used to generate SMC structures. This process includes isothermal deformation with intermediate annealing and gradual step-by-step reduction in the temperature of TMP.

High-strain TMP at temperatures of $0.6-0.78 \mathrm{~T}_{\mathrm{m}}$ refined the MC structure to a grain size of $0.5-0.3$ $\mu \mathrm{m}$, as shown in Figure 4. Elongated $\delta$-phase particles, with lengths from 0.2 to $0.6 \mu \mathrm{m}$, were distributed primarily at grain boundaries. Some coarse second phase particles (up to $1 \mu \mathrm{m}$ ) were still present. This suggests localization of the deformation in the softer matrix, which may have been due to insufficient 
accumulated strain. It is important to note that the SMC structure was a non-equilibrium structure, as indicated by the high dislocation density both within the grains and along the grain boundaries. The grain boundary contrast that is typical of high-angle grain boundaries was not observed (Figure 1b). Post-deformation annealing provides an SMC structure with equilibrium grain boundaries; however, the elastic stresses were not completely removed.

\section{$\underline{3.4 \text { Formation of Nanocrystalline Structures }}$}

Further deformation at lower temperatures of $0.18-0.53 \mathrm{~T}_{\mathrm{m}}$ (room temperature to $\sim 850^{\circ} \mathrm{C}$ ) generated an NC structure with grain sizes of $0.03-0.08 \mu \mathrm{m}$, as shown in Figure 5. TEM analysis of alloy $718 \mathrm{in}$ the NC state revealed that the microstructure was similar to those observed in other NC materials [8]. Significant microstructure refinement to a NC scale has been generated by severe plastic deformation at room temperature using the combined deformation scheme (compressions plus torsion on a Bridgman anvil).

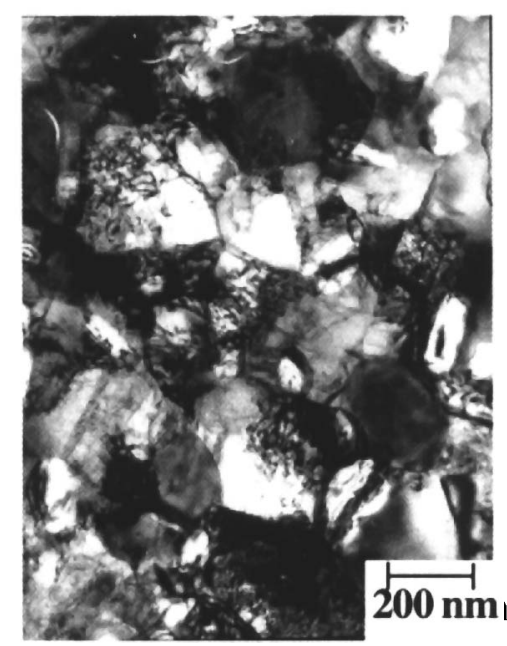

Figure 4. Microstructure of the alloy 718 after forging at a strain rate of $5.5 \times 10^{-3} \mathrm{~s}^{-1}$ and $700^{\circ} \mathrm{C}$ to generate an SMC structure.

The microstructural investigations indicate that after severe plastic deformation, the NC structure is formed in several stages; this is generally consistent with the results of previous investigations on NC materials [8]. At the same time, there were some unique features that were probably due to the nature of this alloy. At the initial stage of deformation a cellular structure was formed. With increasing strain the average cell size decreased from $300 \mathrm{~nm}$ (true strain $=0.03$ ) to $100 \mathrm{~nm}$ (true strain $=0.29$ ). Slip bands were also formed, first in a single direction (true strain $=0.12$ ), and then in two directions, as the strain was increased (true strain=0.29), as shown in Figure 6(a) and (b). At true strains of 0.65 to 1.24 , the cells transform into grains with a size $30-40 \mathrm{~nm}$, as shown in Figure 6(c).

Figure 7 indicates that the microhardness increases with increasing strain in a non-linear manner. There is a region (true strain $=0.03-0.29$ ) where the microhardness does not increase with increasing strain. Increasing the strain from 0.03 to 0.07 increases the microhardness from $5 \mathrm{GPa}$ to only $5.2 \mathrm{GPa}$; this
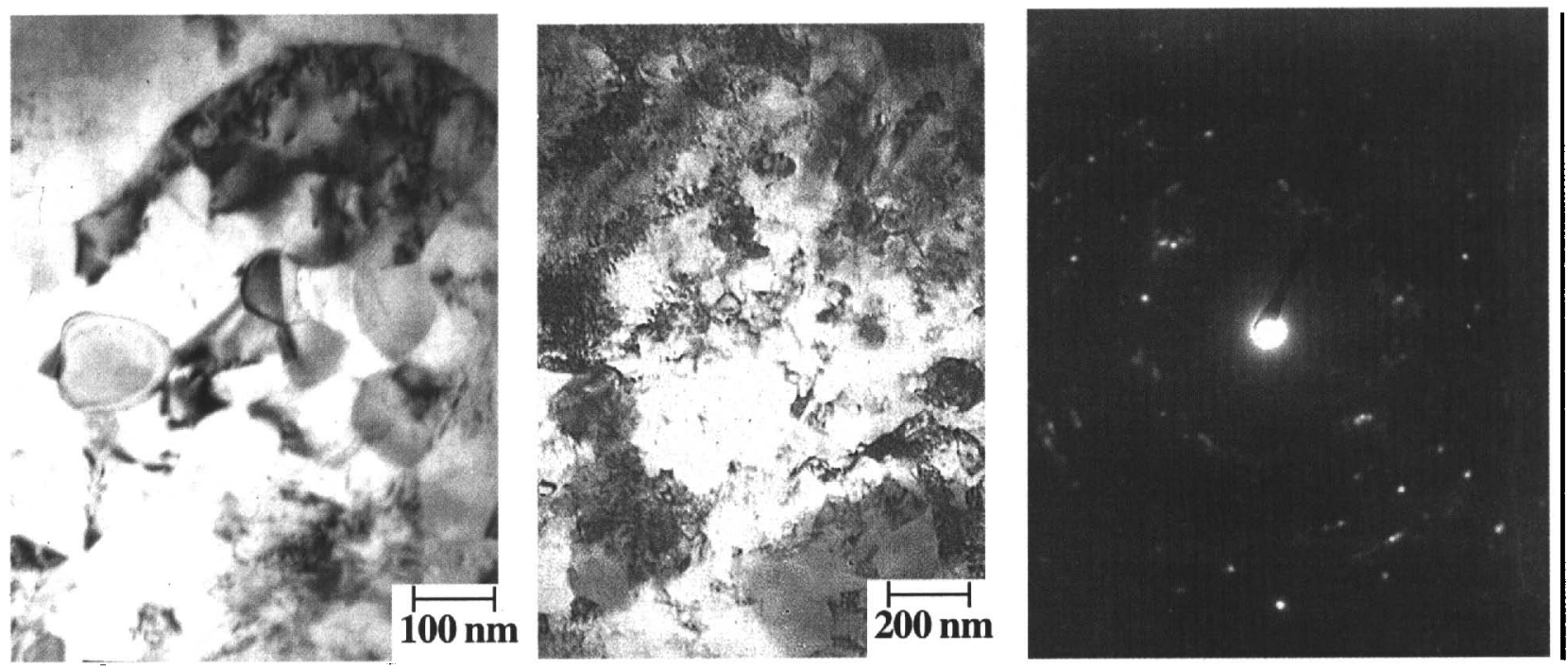

Figure 5. Microstructure of the alloy 718 after forging at $0.53 \mathrm{~T}_{\mathrm{m}}$ to generate an $\mathrm{NC}$ structure. 


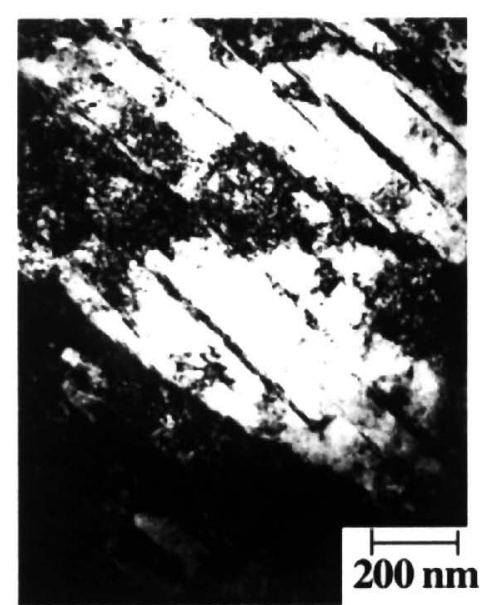

(a)

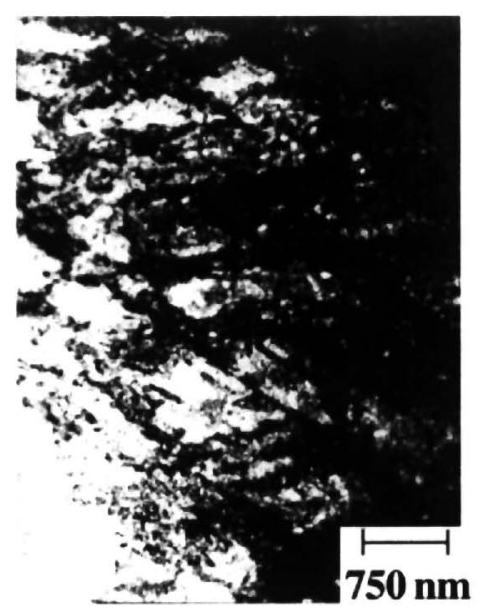

(b)

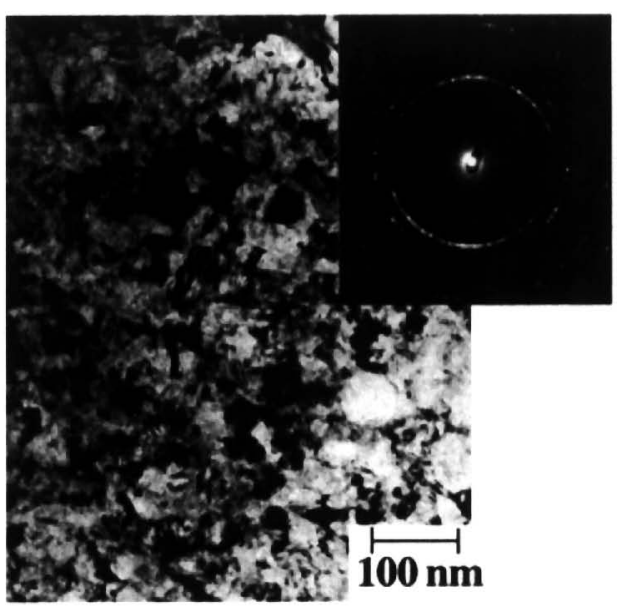

(c)

Figure 6. Microstructure of the alloy 718 after severe plastic deformation at $0.18 \mathrm{~T}_{\mathrm{m}}$ : (a) true strain $=0.12$; (b) true strain $=0.29$; (c) true strain $=1.24$.

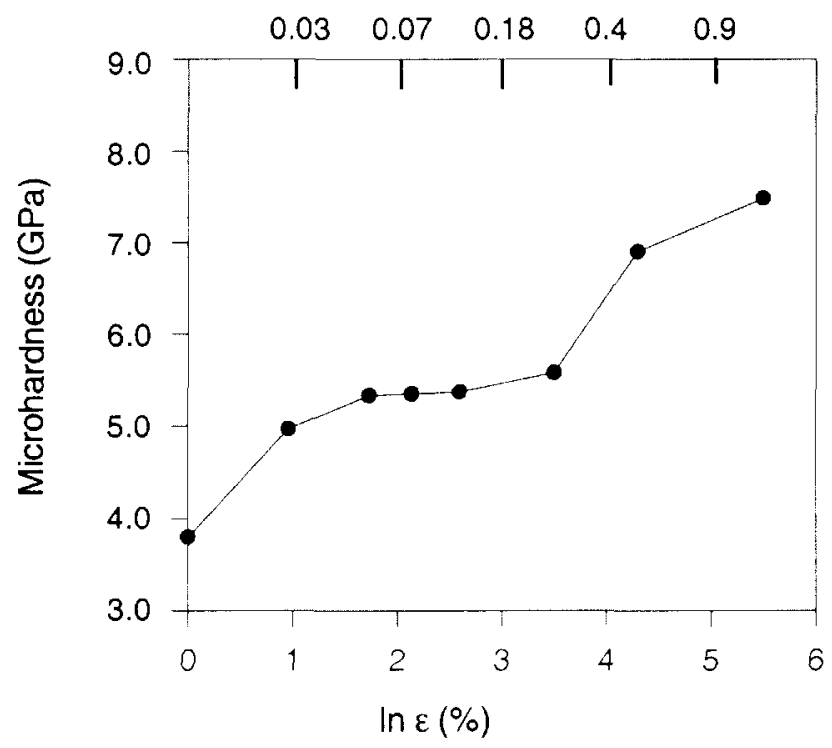

Figure 7. Microhardness versus strain; the strain was determined using equation (1).

plateau in the strain-hardness curve is probably associated with the formation of a cellular structure. On increasing the strain from 0.07 to 0.29 , bands of coarse slip, first in one direction, then in two directions, were observed. A mixed structure consisting of cells and recrystallized grains is formed at the intersection of bands of coarse slip; the size of the cells was in the range of 30 to $50 \mathrm{~nm}$. The plateau in the microhardness-strain curve may also be due to dissolution of second phases. Increasing the strain 0.29 to 1.24 increased the microhardness value from 5.2 to $7.5 \mathrm{GPa}$; in this regime the volume fraction of recrystallized nano-sized grains increase to between 80 and $90 \%$. The microhardness of the NC alloy 718 is twice that of the initial alloy 718 . The increase in microhardness is probably a result of the small grain size of the NC structure, and internal stresses within the grains.

\subsection{Microstructure and Mechanical Properties During SP Deformation}

The mechanical test data from the MC, SMC and NC structures (see Table 2) shows that the mechani- 
Table 2. Superplastic properties of the alloy 718 in the MC, SMC, and NC conditions. The stress $\sigma_{40}$ is the stress at a plastic strain of $40 \%$.

\begin{tabular}{|c|c|c|c|c|c|c|}
\hline \multicolumn{2}{|c|}{ Grain size (particles), $\mu \mathrm{m}$} & \multirow{2}{*}{$\begin{array}{c}\text { Temperature } \\
{ }^{\circ} \mathrm{C} \\
\end{array}$} & \multirow{2}{*}{$\begin{array}{c}\text { Strain rate, } \\
\mathrm{s}^{-1} \\
\end{array}$} & \multirow[t]{2}{*}{$\sigma_{40}, \mathrm{MPa}$} & \multirow{2}{*}{$\begin{array}{c}\text { Strain, } \\
\% \\
\end{array}$} & \multirow[t]{2}{*}{$\mathbf{m}$} \\
\hline$\gamma$ - phase & $\delta$-phase & & & & & \\
\hline $\begin{array}{c}6-12 \\
6\end{array}$ & - & $\begin{array}{c}930-980 \\
\mathbf{9 8 0}\end{array}$ & $5 \times 10^{-4}$ & 70 & 514 & $\begin{array}{r}0.7-0.9 \\
\mathbf{0 . 5}\end{array}$ \\
\hline $1-2$ & $0.15-0.6$ & $\begin{array}{l}950 \\
900 \\
900 \\
800 \\
800 \\
700 \\
650\end{array}$ & $\begin{array}{c}5.5 \times 10^{-4} \\
5.5 \times 10^{-3} \\
5.5 \times 10^{-4} \\
5.5 \times 10^{-3} \\
1.5 \times 10^{-4} \\
3 \times 10^{-4} \\
5.5 \times 10^{-4} \\
\end{array}$ & $\begin{array}{c}\mathbf{6 3} \\
\mathbf{2 2 6} \\
\mathbf{9 6} \\
205 \\
\mathbf{1 3 4} \\
563 \\
742\end{array}$ & $\begin{array}{c}660 \\
215 \\
480 \\
140 \\
390 \\
170 \\
85\end{array}$ & $\begin{array}{c}\mathbf{0 . 6} \\
\mathbf{0 . 3 1} \\
\mathbf{0 . 4} \\
0.2 \\
\mathbf{0 . 3 3} \\
0.2 \\
0.1\end{array}$ \\
\hline 0.3 & $0.1-0.6$ & $\begin{array}{l}900 \\
800 \\
800 \\
800 \\
700 \\
700 \\
700 \\
650 \\
650 \\
600 \\
600\end{array}$ & $\begin{array}{c}\mathbf{5 . 5} \times 10^{-4} \\
\mathbf{5 . 5} \times 10^{-3} \\
\mathbf{5 . 5} \times 10^{-4} \\
\mathbf{1 . 5} \times 10^{-4} \\
5.5 \times 10^{-3} \\
\mathbf{5 . 5} \times 10^{-4} \\
\mathbf{3} \times 10^{-4} \\
5.5 \times 10^{-3} \\
\mathbf{5 . 5} \times 10^{-4} \\
5.5 \times 10^{-4} \\
1.5 \times 10^{-4} \\
\end{array}$ & $\begin{array}{c}\mathbf{6 5} \\
292 \\
\mathbf{1 2 3} \\
\mathbf{8 7} \\
540 \\
\mathbf{3 0 6} \\
\mathbf{2 2 4} \\
833 \\
\mathbf{5 1 4} \\
838 \\
662\end{array}$ & $\begin{array}{c}\mathbf{7 9 0} \\
\mathbf{2 7 0} \\
\mathbf{4 3 0} \\
\mathbf{1 0 9 5} \\
195 \\
\mathbf{4 4 0} \\
\mathbf{7 0 0} \\
130 \\
\mathbf{3 7 0} \\
110 \\
150\end{array}$ & $\begin{array}{c}\mathbf{0 . 6} \\
\mathbf{0 . 3} \\
\mathbf{0 . 5} \\
\mathbf{0 . 5 4} \\
0.29 \\
\mathbf{0 . 3 5} \\
\mathbf{0 . 4 1} \\
0.2 \\
\mathbf{0 . 3} \\
0.15 \\
0.2\end{array}$ \\
\hline \multirow{2}{*}{\multicolumn{2}{|c|}{$0.08-0.1$}} & 600 & $3 \times 10^{-4}$ & 573 & 154 & 0.31 \\
\hline & & 600 & $1.5 \times 10^{-4}$ & 414 & 350 & 0.37 \\
\hline
\end{tabular}

cal behavior of alloy 718 is consistent with refinement of the microstructure. Table 2 indicates that decreasing the grain size from 6 to $0.08 \mu \mathrm{m}$ reduces the lower temperature limit for superplasticity. Additional refinement of the microstructure to $\mathrm{SMC}$ and $\mathrm{NC}$ sizes further reduces the lower temperature limit for superplasticity. Alloy 718 with SMC-NC structure displays SP properties even at $600^{\circ} \mathrm{C}$; the lowest flow stress was observed for the NC structure.

Analysis of the microstructural changes of the MC structure after SP deformation has shown that after deformation at a strain rate of $7 \times 10^{-3} \mathrm{~s}^{-1}$ and temperatures 800 to $1050^{\circ} \mathrm{C}$ the microstructure remains fine-grained. The mean grain size increases from $3.8 \mu \mathrm{m}$ at $900{ }^{\circ} \mathrm{C}$ up to $8.3 \mu \mathrm{m}$ at $1050{ }^{\circ} \mathrm{C}$. On increasing the strain rate from $7 \times 10^{-4} \mathrm{~s}^{-1}$ up to $2 \times 10^{-2} \mathrm{~s}^{-1}$ at $925^{\circ} \mathrm{C}$, the grains remain equiaxed, and their mean size $(\sim 5 \mu \mathrm{m})$ did not change significantly.

The microstructures of the SMC and NC alloy 718 samples were also still equiaxed after SP deformation. The SP deformation also provided a structure that was closer to equilibrium. The density of dislocations decreased, some grain growth was observed, and non-equilibrium grain boundaries were converted to equilibrium boundaries, as indicated by the band contrast observed in the TEM. At temperatures above $900^{\circ} \mathrm{C}$, the SMC alloy 718 grain size was greater than $1 \mu \mathrm{m}$. After deformation at $600^{\circ} \mathrm{C}$ the grain size of the $\mathrm{NC}$ alloy 718 increased up to $0.1 \mu \mathrm{m}$. 


\subsection{Diffusion Bonding and SP Forming}

Diffusion bonding of alloy 718 was investigated using the samples with coarse-grain, MC and SMC structures together with deformation in vacuum. The results obtained demonstrate that a sound solidstate bond can be produced at $0.76 \mathrm{~T}_{\mathrm{m}}\left(\sim 950^{\circ} \mathrm{C}\right)$ and higher at strain rate $\sim 10^{-4} \mathrm{~s}^{-1}$ using alloy 718 with a coarse grain micro structure. At $0.76 \mathrm{~T}_{\mathrm{m}}$ in some areas of the solid-state bond line, recrystallized grains (2-3.5 $\mu \mathrm{m})$ were observed, and these indicate the occurence of dynamic recrystallization/grain growth near the interface. In the MC alloy $718(1 \mu \mathrm{m})$, diffusion bonding at $\sim 0.76 \mathrm{~T}_{\mathrm{m}}$ generated a solid-state bond of good quality.

The solid-state bond of the best quality was produced in SMC alloy 718 at a temperature that is 100 $200^{\circ} \mathrm{C}$ below the optimum temperature for SP forming of a material with MC structure [9]. Sheets were made ( $40 \times 40 \mathrm{~mm}, 0.5-0.6 \mathrm{~mm}$ thick) with $\mathrm{MC}$ and SMC structures by SP forming. Prior to SP forming the sheets were processed to uniform structure in all directions. The grain sizes were $1 \mu \mathrm{m}$ for the MC structure and $0.3 \mu \mathrm{m}$ for the SMC structure. As a result of SP forming at the correct temperature-strain rate conditions for superplasticity (Table 2) semi-spherical shaped parts were produced of the alloy with MC and SMC structures. Refinement of the structure to $1 \mu \mathrm{m}$ and less reduced the SP forming temperature by 50 to $100^{\circ} \mathrm{C}$ as compared with the SP forming technology previously reported [9].

\section{Discussion}

These results show that in alloy 718 the microstructure can be refined to a scale of tens of nanometers by high strain TMP. Analyses of the SMC and NC structures formed in alloy 718 suggests that they were analogous to other materials with SMC and NC structures [4-5]. These structures can be characterized by a high level of residual stress, both within the grains and at the grain boundaries, as indicated by the high dislocation density (non-equilibrium state) in these regions.

The investigation of superplasticity in alloy 718 shows that alloy 718 can display high ductility at relatively low deformation temperatures. The same ductility is observed in the nickel alloys with microduplex structure at high temperatures but at lower strain rates and a higher flow stresses [1-3]. The structural changes that occurred during low-temperature superplasticity were similar to those observed at usual temperatures for superplasticity. In the case of the SMC structure, the peak stress on the grain boundaries is significantly less, because grain boundary sliding leads to more effective stress relaxation.

Comparison of the behavior of alloy 718 with MC, SMC and NC structures suggests that analogous microstructural transformations occur during SP deformation; these include retention of equiaxed grain morphologies and grain growth. At the same time, the increase in the total area of intergranular and interphase boundaries, and the increase in the dislocation density at the grain boundaries, provided low temperature SP behavior. Finally, SP deformation generated a structural condition closer to equilibrium as a result of the transformation of "non-equilibrium grain boundaries" to lower energy boundaries; these boundaries are similar to those usually observed after annealing of SMC and NC materials [6].

These results have demonstrated that microstructure refinement to $1 \mu \mathrm{m}$ and less contributes to a significant decrease in the temperature of the solid-state bonding of bulk materials and the SP forming temperature. The data obtained were in good agreement with the data reported elsewhere [10] on the study of the effect of grain size on the formation of solid-state bonds and formability of a Ti alloy under SP conditions. The production of SMC and NC structures could contribute to a significant expansion of technological opportunities for diffusion bonding and SP forming of nickel base alloys, and alloy 718 in particular. 


\section{Summary}

1. High strain thermo-mechanical processing with a progressive reduction in the deformation temperature has been used to generate MC, SMC and NC structures in alloy 718 .

2. During SP deformation of alloy 718 with MC, SMC and NC structures, similar microstructural transformations were observed. This suggests that for all these structures SP deformation was controlled by a similar mechanism.

3. The influence of the initial grain size on SP deformation of alloy 718 was also studied. Low-temperature superplasticity was observed in SMC and NC alloy 718. For grain sizes of $0.1-0.08 \mu \mathrm{m}$, superplasticity $(\delta=350 \%, m=0.37)$ was observed at a temperature of $600^{\circ} \mathrm{C}$ and a strain rate of $1.5 \cdot 10^{-4} \mathrm{~s}^{-1}$.

4. In comparison with the MC structure, the SMC and NC structures allow a reduction in the lower temperature limit of superplasticity by $200-350^{\circ} \mathrm{C}$, and a decrease in the flow stress by a factor of $1.5-2$.

\section{Acknowledgements}

The authors would like to acknowledge the guidance and support of T.B. Cox, P.S. Follansbee, and J. C. Shei, in arranging the inter-laboratory collaboration between GE-CRD and IMSP. The authors would also like to thank Drs. R.V. Safiullin and R.Y. Lutfullin for help with the diffusion bonding and SP forming experiments.

\section{References}

[1] O.A. Kaibyshev, F.Z. Utyashev, V.A. Valitov, Metal. Term. Obr. Met., N7 (1989), 40-44.

[2] O.A. Kaibyshev, Superplasticity of Alloys, Intermetallides and Ceramics, Springer Verlag, Berlin (1992), 316.

[3] V.A. Valitov, F.Z. Utyashev, Sh. Kh. Mukhtarov, Mat. Sci. For. 304-306 (1999), 79-84.

[4] V.A Valitov, G.A. Salishchev, Sh.Kh. Mukhtarov, Mat. Sci. For, ICSAM97 243-245 (1997), 557.

[5] V.M. Imaev, et al., Scripta Mater., Vol. 40, No. 2(1999), 183-190.

[6] R.Z. Valiev, A.V. Korznikov, R.R. Mulyukov, Mater. Sci. Eng. Al68, (1992), 141.

[7] G.A. Salishchev, O.R. Valiakhmetov, V.A. Valitov, Sh. Kh. Mukhtarov, Mat. Sci. For. 170-172 (1994), 121.

[8] Yu.V. Ivanisenko, A.V.Korznikov, I.M. Safarov, R.Z.Valiev. Nanostructured Materials 6 (1995), 433-436.

[9] INCONEL Alloy 718SPF, A Superalloy for Superplastic Forming, Inco Alloys International, Inc. (1994), p. 14.

[10] O.A. Kaibyshev, R.V. Safiullin, R.Y. Lutfullin, V.V. Astanin, Journal of Materials Engineering and Performance, 8 (2) (1999), 205-210. 